\title{
A graph search algorithm: Optimal placement of passive harmonic filters in a power system
}

\author{
M. Aghaei and A. Dastfan* \\ Electrical Engineering Department, University of Shahrood, Shahrood, Iran. \\ Received 02 June 2013 Accepted 29 April 2015 \\ *Corresponding author: dastfan@shahroodut.ac.ir (A. Dastfan).
}

\begin{abstract}
The harmonic in distribution systems becomes an important problem due to an increase in nonlinear loads. This paper presents a new approach based on a graph algorithm for optimum placement of passive harmonic filters in a multi-bus system, which suffers from harmonic current sources. The objective of this paper is to minimize the network loss, the cost of the filter and the total harmonic distortion of voltage, and also enhances voltage profile at each bus effectively. Four types of sub-graph have been used for search space of optimization. The method handles standard capacitor sizes in planning filters and associated costs. In this paper, objective function is not differential but eases solving process. The IEEE 30 bus test system is used for the placement of passive filter. The simulation has been done to show applicability of the proposed method. Simulation results prove that the method is effective and suitable for the passive filter planning in a power system.
\end{abstract}

Keywords: Harmonics, Passive Filter, Optimization, Graph Algorithm.

\section{Introduction}

The increase of current and voltage harmonics levels in power systems is caused through a growth in nonlinear loads. The harmonic of voltages and currents in power system are generated mainly due to the application of power electronic convertor, switching devices, and transformer's saturation [1]. Power electronic devices show nonlinear load features and thus they create distorted currents even when supplied with a purely sinusoidal voltage. These distorted currents cause current and voltage distortion throughout the power system. To improve power quality, several methods exist such as the use of higher-pulse converters, the choice of transformer connections, the modification of electric circuit configuration, and the application of active and passive harmonic filters [1]. Among them, passive harmonic filters (PHF) cause low impedance shunt paths for harmonic currents and compensate reactive power through its capacitor at the fundamental frequency. Low maintenance, cost, and complexity are the main advantages of PHF compare to other solutions such as active power filter. The PHFs have several disadvantages such as parallel and series resonances, aging of passive components, and dependency on the source impedance, which should be considered in PHF designing [2].

Since the PHF planning is a nonlinear programming problem, it is difficult to solve by conventional approaches such as a blind search. Many methods have been devised for an optimal PHF planning in the literature. Conventional methods of search and optimization are slow in finding a solution in a very complex search space $[3,4]$. Hence, some methods such as artificial neural networks (ANNs) [5] or genetic algorithms (GAs) [6,7] are widely applied for searching an optimal solution of locating and sizing passive filters. In many cases, the difficulties of GA method are the computing of efficiency and convergence because it contains selection, copy, crossover and mutation and so on. For instance, Eberhart and Kennedy recently suggested a particle swarm optimization (PSO) based on the analogy of swarm of bird and school of fish [8]. PSO algorithm uses as a branch of stochastic techniques to explore the search space for 
optimization. In $[9,10]$ a probabilistic approach is used for filter planning that requires stochastic calculation in a large range. Reference [11] presents a method which combines the orthogonal array experiment technique and an ant direction hybrid differential evolution algorithm for optimal passive harmonic filter planning.

This paper presents a practical technique based on a graph search method for filter placement problem.

The proposed algorithm determines the number, sizes, and locations of filters to be placed on a distribution system in order to minimize cost. The optimization algorithm treats capacitor sizes as discrete variables and uses standard sizes and exact capacitor costs.

\section{Problem formulation}

The main objectives are to minimize the filter cost, the network power losses and total harmonic distortion of voltages while satisfying the harmonic standard and improving voltage profile. In this paper, the following assumptions have been made:

- Rated voltage will not be affected by the addition of filters,

- consider linear and nonlinear loads in a balanced three-phase system.

\subsection{Constraints}

Voltage constraints will be considered by specifying upper and lower bounds of rms voltage. (e.g., $\mathrm{v}^{\min }=0.9 \mathrm{pu}, \mathrm{v}^{\max }=1.1 \mathrm{pu}$ )

$V^{\min } \leq \sqrt{\sum_{h}\left(V_{i}^{(h)}\right)^{2}} \leq V^{\max }$, for $\quad i=1, \ldots, n$

Where $\mathrm{i}, \mathrm{h}$ denotes bus number and harmonic order, respectively.

The distortion of voltage is considered through specifying maximum total harmonic distortion $\left(T H D_{v, i}\right)$, voltages and currents at system bus:

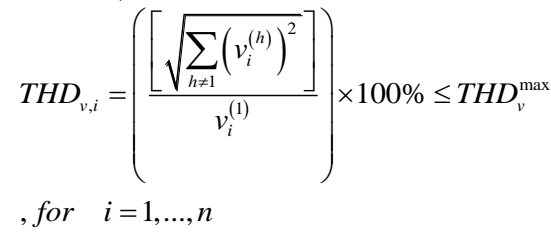

Bounds of values for (1) and (2) are specified by the IEEE-519 standard limits [16].

\subsection{Objective Function}

The problem of optimization can be stated as follows:

$$
\begin{aligned}
\min f= & (K V T H D)+\left(K_{A} \text { Ploss }\right) \\
& +\left(k_{v} \text { profv }\right)+\left(k_{c f p} Q\right)
\end{aligned}
$$

where, VTHD sum of voltage total harmonic distortion deviation from standard limits,

Ploss Total network losses,

profv Sum of voltages deviation from 1 per unit at each bus,

$Q$ Size of filter capacitor in $\mathrm{kVAR}$,

$K_{A}$ Cost per MW (e.g., $K_{A}=120 \$ / \mathrm{MW}$, [14])

$K_{c f p}$ Cost per kVAR of fixed capacitance

$K_{V}$ a factor to convert voltages deviation from 1 per unit to dollars;

$K$ a factor to convert THD deviation from standards to dollars.

Network losses consist of two parts. The first part is computed by differencing between generated and loaded power at fundamental frequency and the second part is computed through using harmonic power flow outputs as follows:

$$
P_{\text {loss }}=\sum_{h=1}^{L}\left[\sum_{i=1}^{n} \sum_{j=1(j<i)}^{n} V_{i}^{(h)} V_{j}^{(h)} Y_{i j}^{(h)} \times\left(\theta_{i}^{(h)}-\theta_{j}^{(h)}-\delta_{i j}^{(h)}\right)\right]
$$

where, $V_{i}^{(h)}$ and $\theta_{i}^{(h)}$ are magnitude and phase of hth harmonic voltage at bus $i$ and $Y_{i j}^{(h)}$ and $\delta_{i j}^{(h)}$ are magnitude and phase of hth harmonic line admittance between buses $i$ and $j$, respectively.

\section{The graph search algorithm}

A graph is made of a set of nodes that are connected by arcs. Each node corresponds to a possible combination of the size of filters capacitor and locations of filters for a given number of filters to be placed. A specific graph is used for each possible number of filters to be placed. The proposed algorithm searches the nodes of graph in an attempt to determine the optimal solution. Beginning with minimum number of filters to be placed (a user-specified parameter); a search is performed to locate the node in that graph which produces minimum cost. If the determined maximum number of filters (a user-specified parameter) has not been reached, the number of filters to be placed is incremented by one and the next graph is searched. Values of costs for every node are determined on each graph, and another filter will increase overall cost. Then, the process is terminated.

\subsection{Definition of the graph nodes and arcs}

A complete graph for a given number of filters contains several nodes from which each one corresponds to a possible combination of filter capacitor sizes and locations of filters. In the huge power networks, the number of nodes that must be examined can be very large, and an effective 
procedure was developed to allow only a relatively small percentage of nodes to be evaluated to determine a near-optimal solution. Thus, the following four different types of arcs have been defined so the algorithm can move from one node to another based on the rules of these four types of arcs in search of the optimal solution.

\subsubsection{Type I arcs}

This type of arcs changing one filter capacitor size only with locations remaining unchanged and moving from one node to another is defined as "Type I" move.

\subsubsection{Type II arcs}

Type II represents a change of one filter location only. These arcs require the nodes on both sides that have the same capacitor size. In addition, the buses specified must be electrically adjacent to another. Move from one node to another using this type of arc is referred to as "Type II" move.

Since in both Types I and II moves, there is only a change in one decision variable; therefore, these moves can be considered as "local variations". For example, suppose that two single-tune filters are to be placed on two buses in a distribution system. Assume the initial node corresponds to a solution that places at buses 5, 14 with capacitor sizes 600 $\mathrm{kVAR}$. Standard capacitor sizes in use are 150, 300, 450, 600, $750 \mathrm{kVAR}$, and so on. Possible Types I and II moves from this initial node are shown in figure 1 . These "adjacent" moves would be evaluated in a systematic manner until a decrease in costs is determined. Once this occurs, the new node will be center node for starting possible moves.

\subsubsection{Type III arcs}

An arc of this type represents a simultaneous change in the size and location of a single filter. These changes are allowed to electrically adjacent busses at the location of filter and capacitor size only changes by one step according to a typical capacitor size in use. This move type is referred to as "Type III" move. For the initial node, possible Type III moves from this node are shown in figure 2.

\subsubsection{Type IV arcs}

This type of arcs location of filter changes to another bus that is not necessarily adjacent to the existing location. This arcs type connects all nodes that differ only in the location of a single filter, with all sizes of capacitors and all other locations of filters unchanged. Moves of this type are referred to as "Type IV" moves. For the initial node, all possible moves of this type are shown in figure 3 .

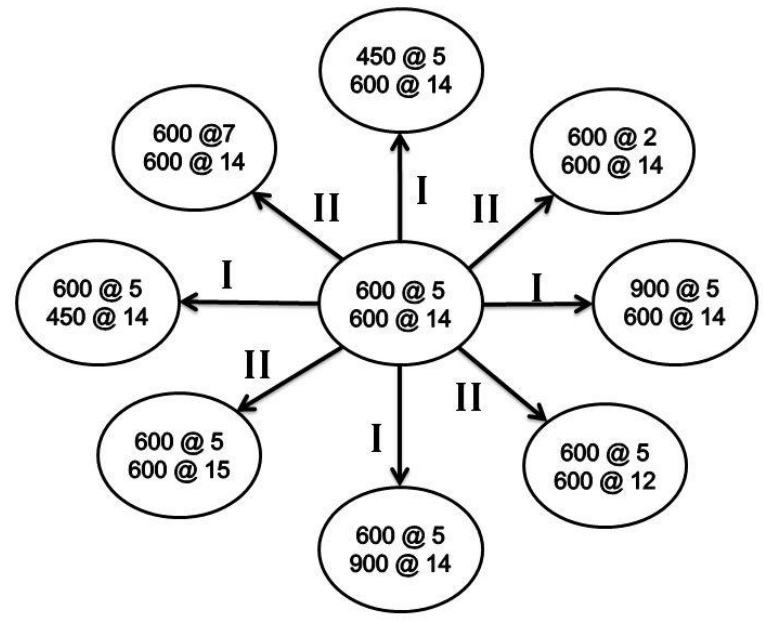

Figure 1. Possible types I and II moves.

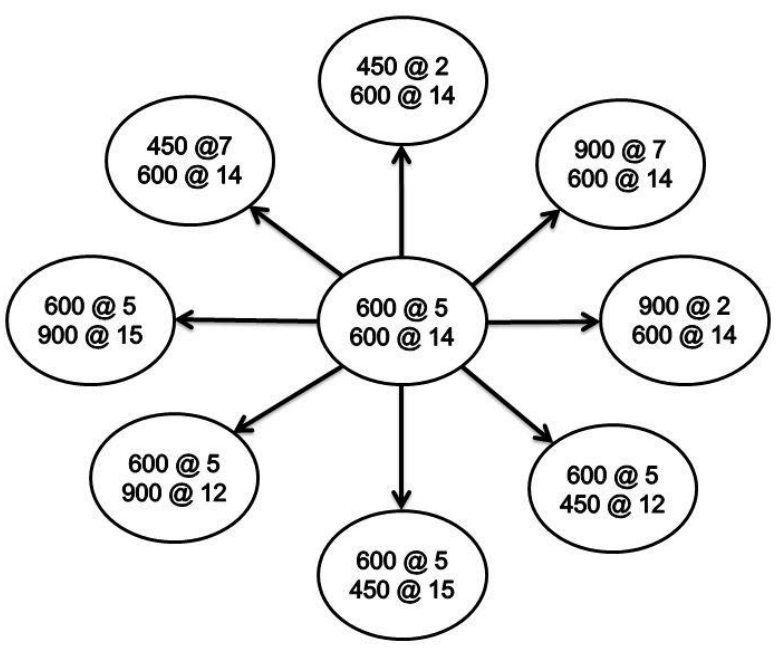

Figure 2. Possible type III moves.

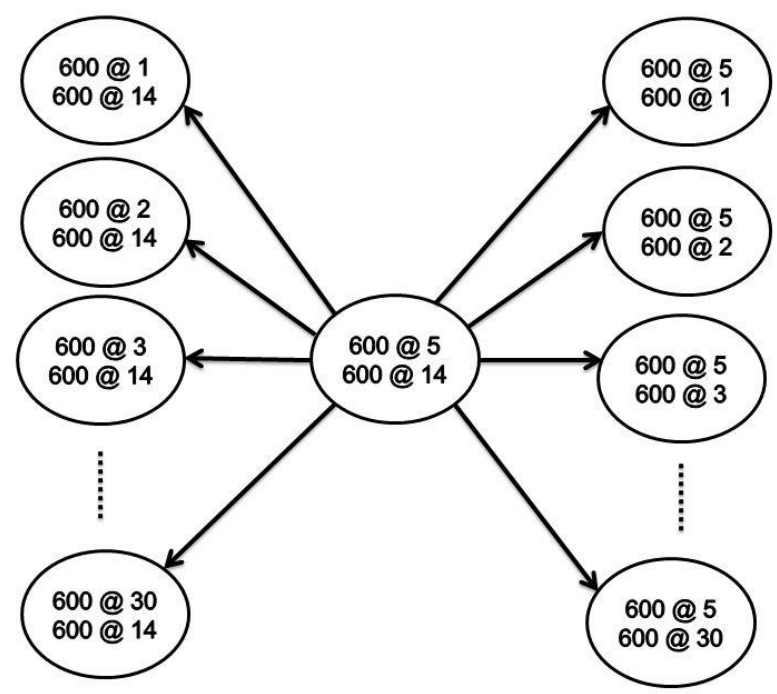

Figure 3. Possible type IV moves.

The purpose of Types III and IV moves is to allow the algorithm to escape from local minimums that 
may be encountered in search of the global optimum. These moves were found to produce good results, often allowing escape from a local minimum. This algorithm implemented allows the user to specify the moves to be considered.

\subsection{The overall solution procedure}

Step 1: Consider the user specified minimum number of filters to be placed in network.

Step 2: Choose an initial solution for these numbers of filters, or let the computer randomly select one creating the initial node in the graph.

Step 3: Evaluate Types I and II moves in a systematic manner. Any move, which causes a decrease in objective function, is immediately accepted and creates new node in our graph and other possible arcs from this node are denied. Then, a new node is centered for evaluating Types I and II moves. This process should be continued until no further improvements in costs can be made. At this point, a local optimum solution for the network has been obtained.

Step 4: Evaluate Type III moves in a systematic manner after no further improvement can be made with Type I or II moves. If any Type III move is accepted, again Types I and II moves should be returned to Step 3 for evaluation. If all Type III moves fail, go to next Step.

Step 5: Ultimately evaluate Type IV moves. Once any Type IV move is accepted, return to Step 3 for evaluation of Types I and II moves. If all moves of Type IV fail, the near-optimal solution for these numbers of filters has been found. Go to Step 6.

Step 6: Compare the objective function resulting from this solution to the objective function with the previous number of filters. If the new objective function is decreased, increase the number of filters and return to Step 2. Otherwise, the algorithm terminates. The solution corresponding to the previous number of filters is the overall near-optimal solution.

\section{Test case system}

In order to test and validate our method for planning passive filter, the IEEE 30 bus test system from [15] was implemented and is showed in figure 4. The system data is shown in tables A.1 and A.2 (see Appendix). All loads in the network are linear except for, four nonlinear loads, which are located at busses 5, 14, 21 and 30. These nonlinear loads are 6-pulses diode rectifiers. Due to the existence of these power electronic devices, considerable harmonic currents are injected into the system. Harmonic currents in per unit are shown in table 1 . Simulation result shows about 24.1052 MW losses without the presence of filters. The voltages profile and total harmonic voltage distortion $\left(\mathrm{THD}_{\mathrm{v}}\right)$ at each bus are determined through no passive filter in the system. In order to compensate harmonics, single-tune passive filter for low order harmonics and high pass filter for higher order harmonics are used in this network that is most common shunt filter types.

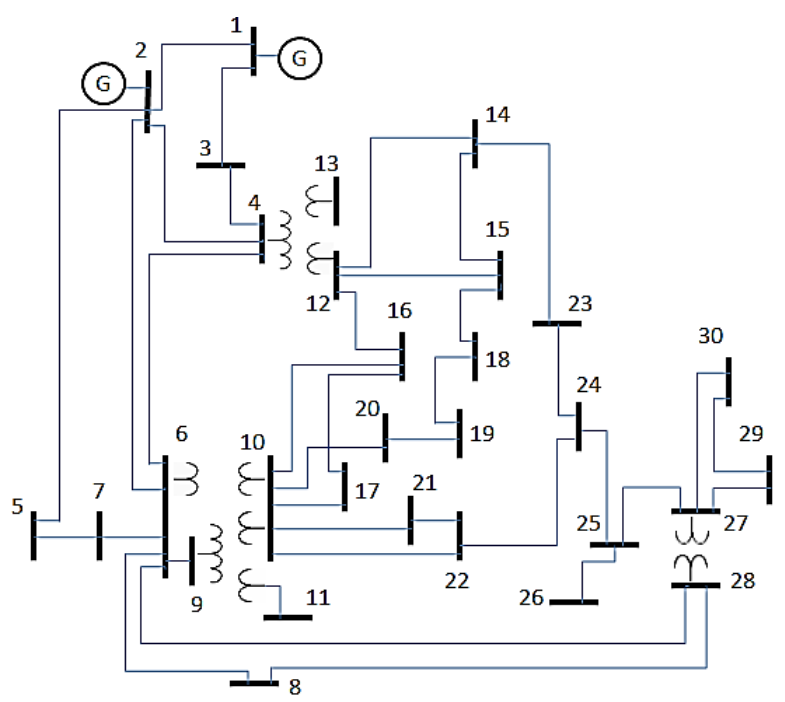

Figure 4. The IEEE 30 bus test system.

Table 1. Harmonic currents in per unit for IEEE 30 bus test system.

\begin{tabular}{|c|c|c|c|c|}
\hline Bus & 5 & 14 & 21 & 30 \\
\hline$h=5$ & 0.0072 & 0.0128 & 0.0416 & 0.0082 \\
\hline$h=7$ & 0.0051 & 0.0091 & 0.0297 & 0.0059 \\
\hline$h=11$ & 0.0033 & 0.0058 & 0.0189 & 0.0037 \\
\hline$h=13$ & 0.0028 & 0.0049 & 0.0160 & 0.0032 \\
\hline$h=17$ & 0.0021 & 0.0038 & 0.0122 & 0.0024 \\
\hline$h=19$ & 0.0019 & 0.0034 & 0.0109 & 0.0022 \\
\hline$h=23$ & 0.0016 & 0.0028 & 0.0090 & 0.0018 \\
\hline$h=25$ & 0.0014 & 0.0026 & 0.0083 & 0.0016 \\
\hline
\end{tabular}

\subsection{Simulation results}

To determine the global optimum solution for locating passive filters, the graph search algorithm is used. Two passive filter packs are placed at buses 2, 21 with capacitor size $600 \mathrm{KVAR}$, and this state is considered as initial node for starting our approach. By processing algorithm, the number of filters is increased and results related to each stage are obtained. The first stage of optimization is to find optimum location and capacitor size for two filter packs. Graph algorithm offers an optimum solution based on 
locating these filter packs at busses 1 and 9 with capacitor sizes of 0.6, 3.6 KVAR, respectively. By increasing the number of filters to 3 , and finding optimum location and capacitor size for those filters, the objective function shows an improvement to this change, and so the process continues. The decrement of objective function goes on until there are six filter packs in the network. However, on this stage, objective function shows an increasing trend against previous stages. This increase is a sufficient reason to terminate the optimization process. Therefore, this algorithm suggests five filter packs to be located at this test system for mitigation harmonics. The final result is to locate five filter packs at busses $1,5,8,21$ and 30 with capacitor sizes $0.45,3.6,3.6,3.6$ and 0.6, respectively. Results from graph algorithm for two to six filter packs are presented in table 2. Network losses are included losses in fundamental frequency and harmonic frequency. Figures 5 shows the voltages profile and figure 6 shows $\mathrm{THD}_{\mathrm{v}}$ before and after installing passive filters at each bus. It shows that the $\mathrm{THD}_{\mathrm{v}}$ is well controlled and voltage profile is improved after the placement of the filters so that values of $\mathrm{THD}_{\mathrm{v}}$ satisfy the standard limits. Minimum voltage occurs in bus 7 with value 0.945 per unit and maximum voltage at bus 1 with value 1.06 per unit. Also all of the values of $\mathrm{THD}_{\mathrm{v}}$ are below $4.5 \%$.

Table 2. Results on test system.

\begin{tabular}{|c|c|c|c|}
\hline \#filter & location & $\begin{array}{c}\text { Capacitor } \\
\text { size(MVAR) }\end{array}$ & $\begin{array}{c}\text { Network } \\
\text { losses } \\
\text { (MWATT) }\end{array}$ \\
\hline 2 & $\begin{array}{l}1 \\
9\end{array}$ & $\begin{array}{c}0.60 \\
3.6\end{array}$ & 2.8572 \\
\hline 3 & $\begin{array}{c}5 \\
21 \\
27\end{array}$ & $\begin{array}{l}3.9 \\
3.6 \\
3.6\end{array}$ & 2.6284 \\
\hline 4 & $\begin{array}{c}1 \\
10 \\
21 \\
27\end{array}$ & $\begin{array}{l}0.45 \\
3.6 \\
3.6 \\
3.6\end{array}$ & 2.6196 \\
\hline 5 & $\begin{array}{c}1 \\
5 \\
8 \\
21 \\
30\end{array}$ & $\begin{array}{l}0.45 \\
0.36 \\
0.36 \\
0.36 \\
0.60\end{array}$ & 2.5252 \\
\hline 6 & $\begin{array}{c}2 \\
3 \\
7 \\
9 \\
15 \\
29\end{array}$ & $\begin{array}{l}0.36 \\
0.60 \\
0.60 \\
0.36 \\
0.36 \\
0.45\end{array}$ & 2.9412 \\
\hline
\end{tabular}

Figures 7 and 8 show THD of voltage and voltage profile at buses 5, 10, 21 and 30 on each stage of graph algorithm process for different number of filters. As can be indicated, results show that five filter branches located at network buses have improved but increased the number of filters to six. However, no improvement has been seen in results but the algorithm suggests five filter branches as problem global solution.

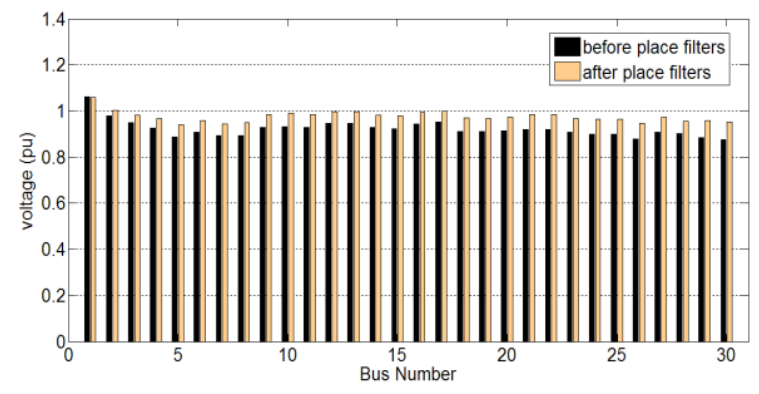

Figure 5. Voltage profile before and after placing filters.

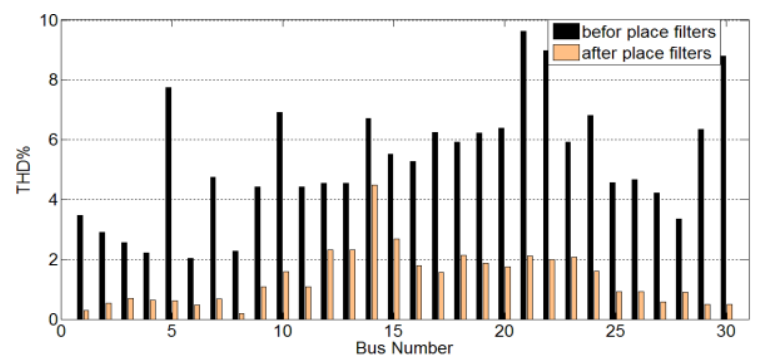

Figure 6. THDV before and after placing filters.

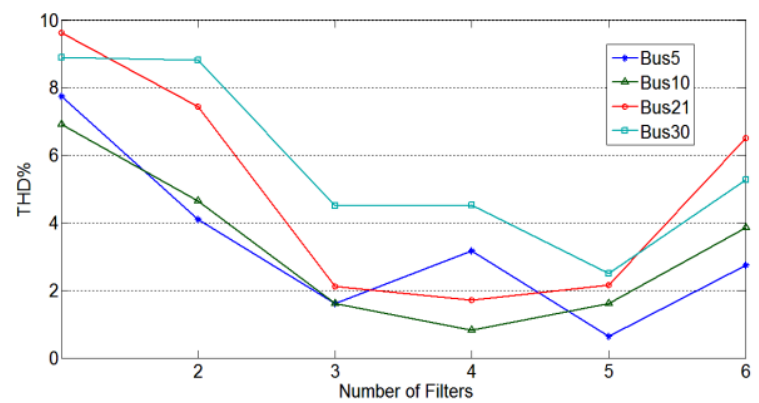

Figure 7. THD of voltage in each stage for four network buses.

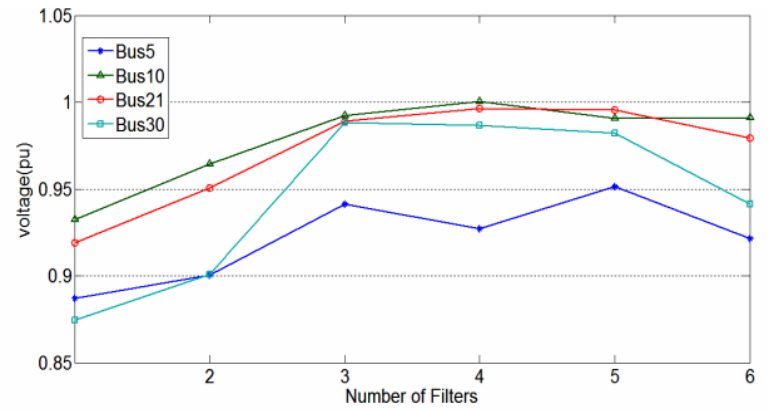

Figure 8. Voltage in each stage for four network buses.

In order to demonstrate the performance of the proposed graph algorithm, some performance comparisons with well-known genetic algorithm (GA) are made. For this purpose, the realistic 18 bus system [17] is used. In [18] the GA is utilized for solving the same problem in 18-bus system. 
Also, we plan passive filters through the graph algorithm in this network. Figures 9 and 10 illustrate the 5th and 7th harmonic voltages in p.u., respectively before and after filter placement using the proposed method and GA.

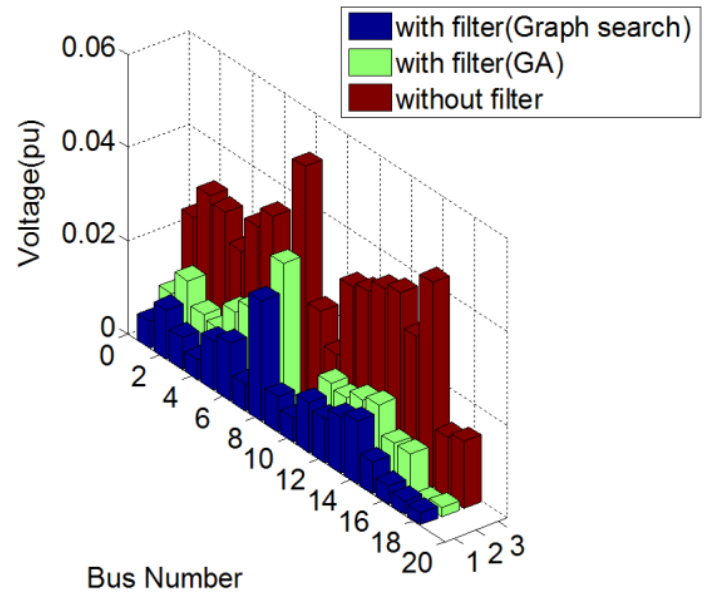

Figure 9. Fifth harmonic voltages before and after filter installation.

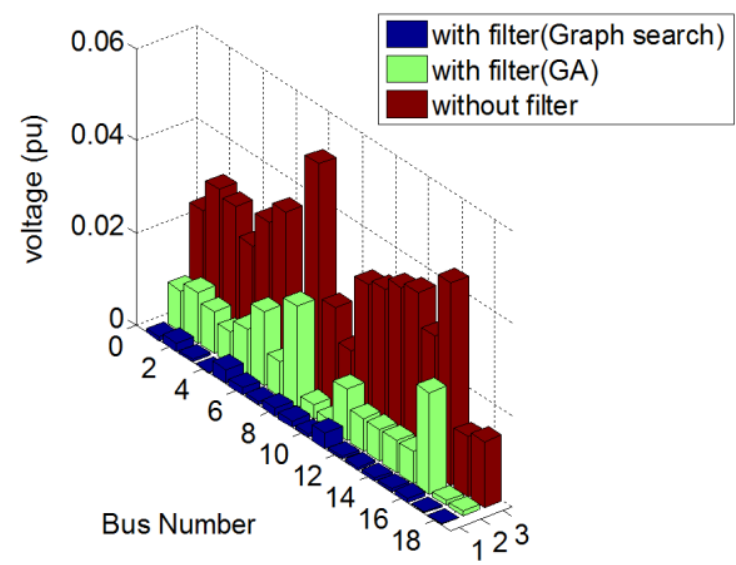

Figure 10. Seventh harmonic voltages before and after filter installation.

These figures show that the proposed this method is very efficient for optimization problems and suitable for planning passive filters in power networks.

In this method, there is no complex calculation for obtaining results on each step of optimization. The only calculation is related to get values of objective function. Because of arcs and nodes are graphical tools to describe space of problem, this method has a good visual comprehension. In this paper, a graph algorithm is applied on two power networks for finding optimum placement of filters and the simulation results show satisfaction of problems, which indicate the graph algorithm is a practical method for the optimization problem.

Using four move types in the proposed method is not necessary for testing all possible states and therefore this algorithm requires less time to converge. Since the more time in this method is spent for doing power flow with using fast power flow methods, this time is decreased. In addition to the optimum placement of filters in power networks, another optimization includes filter parameters optimization, which is studied in [19]. Therefore, these two optimization problems can be focused in future studies.

\section{Conclusion}

This paper has presented a new method for mitigation harmonic with passive harmonic filters design. The approach is a graph search algorithm. It can handle standard capacitor sizes and associated costs. This algorithm does not use a differential objective function which eases solving process. Mathematical simplicity of the method makes it possible to include many features in the algorithm that would be rather difficult with previous solution methods (e.g., the user can constrain the filter locations). The IEEE 30 bus test system is used for placement passive filter for showing the applicability of the proposed method. The simulation results verify the feasibility and the validity of the proposed graph search algorithm in the design of optimal passive harmonic filter of a multi-bus system.

\section{References}

[1] Arrillaga, J. \& Watson, N. R. (2003). Power system harmonics. Second Edition, In: Wiley, J. \& Sons (Eds.), ltd.

[2] Massoud, A. M., Finney, S. J. \& Williams, B.W. (2004). Review of harmonic current extraction techniques for an active power filter, in: 11th International Conference on Harmonics and Quality of Power, pp. 154-159, 2004.

[3] Yan, Y. H., Chen, C. S., Moo, C. S. \& Hsu, C. T. (1994). Harmonic analysis for industrial customers. IEEE Trans. Ind. Applicat. , vol. 30, pp. 462-468.

[4] Makram, E. B., Subramaniam, E. V., Girgis, A. A. \& Catoe, R. (1993). Harmonic filter design actual recorded data. IEEE Trans. Ind. Applicat. , vol. 29, pp. 1176-1182.

[5] Chang, Y-P., Low, Ch. \& Wu, Ch-J. (2007). Optimal design of discrete-value passive harmonic filters using sequential neural-network approximation and orthogonal array. IEEE Transactions On Power Delivery. vol. 22, no. 3, pp. 1813-1821.

[6] Chang, G., Wang, H-L. \& Chu, Sh-Y. (2004). Strategic placement and sizing of passive filters in a power system for controlling voltage distortion. IEEE Transactions on Power Delivery, vol. 19, no. 3, pp. 1204-1211.

[7] Chang, G., Chu, Sh-Y. \& wang, H-L. (2006). A new method of passive harmonic filter planning for 
controlling voltage distortion in a power system. IEEE Transactions on Power Delivery, vol. 21, no. 1, pp. 305-312.

[8] Ko, Ch-N., Chang, Y-P. \& Wu, Ch-J. (2009). A pso method with nonlinear time-varying evolution for optimal design of harmonic filters. IEEE Transactions on Power Systems, vol. 24, no. 1, pp. 437-444.

[9] Chang, G., Wang, H-L. \& Chu, Sh-Y. (2007). A probabilistic approach for optimal passive harmonic filter planning. IEEE Transactions On Power Delivery, vol. 22, no. 3, pp. 1790-1798.

[10] Chang, G., Wang, H-L., Chuang, G-Sh. \& Chu, Sh-Y. (2009). Passive harmonic filter planning in a power system with considering probabilistic constraints. IEEE Transactions on Power Delivery, vol. 24, no. 1, pp. 208-217.

[11] Chang, Y-P., \& Low, Ch. (2008). An ant direction hybrid differential evolution heuristic for the largescale passive harmonic filters planning problem. Expert Systems with Applications. vol. 35, pp. 894-904.

[12] Carlisle, J. C. \& El-Keib, A. A. (2000). A graph search algorithm for optimal placement of fixed and switched capacitors on radial distribution systems. IEEE Transactions on Power Delivery, vol. 15, no. 1, pp.423-428.

\section{Appendix.}

[13] Baghzouz, Y. \& Ertem, S. (1990). Shunt capacitor sizing for radial distribution feeders with distorted substation voltage. IEEE Trans. Power Delivery, vol. 5, pp. 650-657.

[14] Wu, Z. Q. \& Lo, K. L. (1995). Optimal choice of fixed and switched capacitors in radial distributions with distorted substation voltage. Proc. Inst.Elect. Eng., Gen., Transm. Distrib, vol. 142, no. 1, pp. $24-28$.

[15] Saadat, H. Power system analysis. (2002). 2nd edition, E-Publishing Inc, New York. vol. 1, pp. 289298.

[16] IEEE Recommended Practices and Requirements for Harmonics Control in Electric Power Systems. (1992). IEEE Std. 519.

[17] Yan, Y. H., Chen, C. S., Moo, C. S., \& Hsu, C. T. (1994). Harmonic analysis for industrial customers. IEEE Trans. Ind. Appl., vol. 30, no. 3, pp. 462-468.

[18] Hong, Ying-Yi., \& Chiu, Ching-Sheng. (2010). Passive filter planning using simultaneous perturbation stochastic approximation. IEEE Transactions on Power Delivery, vol. 25, no. 2, pp. 939-946.

[19] Dastfan, A., Yassami, H., \& Rafiei, M. R. (2014). Optimum design of passive harmonic filter by using game theory concepts. Intelligence Systems in Electrical Engineering Journal, vol. 4, no. 4, pp. 13-22.

Table A.1.

\begin{tabular}{|c|c|c|c|}
\hline \multicolumn{4}{|c|}{ BUS DATA } \\
\hline Bus & Type & $\begin{array}{l}\text { Load } \\
(\mathrm{MW})\end{array}$ & $\begin{array}{l}\text { Load } \\
\text { (MVAR) }\end{array}$ \\
\hline 1 & PV & 0 & 0 \\
\hline 2 & PV & 21.7 & 12.7 \\
\hline 3 & PQ & 2.4 & 1.2 \\
\hline 4 & PQ & 7.6 & 1.6 \\
\hline 5 & PQ & 94.2 & 19 \\
\hline 6 & PQ & 0 & 0 \\
\hline 7 & PQ & 22.8 & 10.9 \\
\hline 8 & PQ & 30 & 30 \\
\hline 9 & PQ & 0 & 0 \\
\hline 10 & PQ & 5.8 & 2 \\
\hline 11 & PQ & 0 & 0 \\
\hline 12 & PQ & 11.2 & 7.5 \\
\hline 13 & PQ & 0 & 0 \\
\hline 14 & PQ & 6.2 & 1.6 \\
\hline 15 & PQ & 8.2 & 2.5 \\
\hline 16 & PQ & 3.5 & 1.8 \\
\hline 17 & PQ & 9 & 5.8 \\
\hline 18 & PQ & 3.2 & 0.9 \\
\hline 19 & PQ & 9.5 & 3.4 \\
\hline 20 & PQ & 2.2 & 0.7 \\
\hline 21 & PQ & 17.5 & 11.2 \\
\hline 22 & PQ & 0 & 0 \\
\hline 23 & PQ & 3.2 & 1.6 \\
\hline 24 & PQ & 8.7 & 6.7 \\
\hline 25 & PQ & 0 & 0 \\
\hline 26 & PQ & 3.5 & 2.3 \\
\hline 27 & PQ & 0 & 0 \\
\hline 28 & PQ & 0 & 0 \\
\hline 29 & PQ & 2.4 & 0.9 \\
\hline 30 & PQ & 10.6 & 1.9 \\
\hline
\end{tabular}


Table A.2.

\begin{tabular}{|c|c|c|c|c|c|}
\hline \multicolumn{6}{|c|}{ Branch Data } \\
\hline From & To & Type & $\mathbf{R}(\mathbf{p u})$ & $\mathbf{X}(\mathbf{p u})$ & $\mathbf{B}(\mathbf{p u})$ \\
\hline 1 & 2 & Transmission Line & 0.0192 & 0.0575 & 0.0264 \\
\hline 1 & 3 & Transmission Line & 0.0452 & 0.1852 & 0.0204 \\
\hline 2 & 4 & Transmission Line & 0.057 & 0.1737 & 0.0184 \\
\hline 3 & 4 & Transmission Line & 0.0132 & 0.0379 & 0.0042 \\
\hline 2 & 5 & Transmission Line & 0.0472 & 0.1983 & 0.0209 \\
\hline 2 & 6 & Transmission Line & 0.0581 & 0.1763 & 0.0187 \\
\hline 4 & 6 & Transmission Line & 0.0119 & 0.0414 & 0.0045 \\
\hline 5 & 7 & Transmission Line & 0.046 & 0.116 & 0.0102 \\
\hline 6 & 7 & Transmission Line & 0.0267 & 0.082 & 0.0085 \\
\hline 6 & 8 & Transmission Line & 0.012 & 0.042 & 0.0045 \\
\hline 6 & 9 & Transformer & 0 & 0.208 & 0 \\
\hline 6 & 10 & Transformer & 0 & 0.556 & 0 \\
\hline 9 & 11 & Transmission Line & 0 & 0.208 & 0 \\
\hline 9 & 10 & Transmission Line & 0 & 0.11 & 0 \\
\hline 4 & 12 & Transformer & 0 & 0.256 & 0 \\
\hline 12 & 13 & Transmission Line & 0 & 0.14 & 0 \\
\hline 12 & 14 & Transmission Line & 0.1231 & 0.2559 & 0 \\
\hline 12 & 15 & Transmission Line & 0.0662 & 0.1304 & 0 \\
\hline 12 & 16 & Transmission Line & 0.0945 & 0.1987 & 0 \\
\hline 14 & 15 & Transmission Line & 0.221 & 0.1997 & 0 \\
\hline 16 & 17 & Transmission Line & 0.0824 & 0.1923 & 0 \\
\hline 15 & 18 & Transmission Line & 0.107 & 0.2185 & 0 \\
\hline 18 & 19 & Transmission Line & 0.0639 & 0.1292 & 0 \\
\hline 19 & 20 & Transmission Line & 0.034 & 0.068 & 0 \\
\hline 10 & 20 & Transmission Line & 0.0936 & 0.209 & 0 \\
\hline 10 & 17 & Transmission Line & 0.0324 & 0.0845 & 0 \\
\hline 10 & 21 & Transmission Line & 0.0348 & 0.0749 & 0 \\
\hline 10 & 22 & Transmission Line & 0.0727 & 0.1499 & 0 \\
\hline 21 & 22 & Transmission Line & 0.0116 & 0.0236 & 0 \\
\hline 15 & 23 & Transmission Line & 0.1 & 0.202 & 0 \\
\hline 22 & 24 & Transmission Line & 0.115 & 0.179 & 0 \\
\hline 23 & 24 & Transmission Line & 0.132 & 0.27 & 0 \\
\hline 24 & 25 & Transmission Line & 0.1885 & 0.3292 & 0 \\
\hline 25 & 26 & Transmission Line & 0.2544 & 0.38 & 0 \\
\hline 25 & 27 & Transmission Line & 0.1093 & 0.2087 & 0 \\
\hline 28 & 27 & Transformer & 0 & 0.396 & 0 \\
\hline 27 & 29 & Transmission Line & 0.2198 & 0.4153 & 0 \\
\hline 27 & 30 & Transmission Line & 0.3202 & 0.6027 & 0 \\
\hline 29 & 30 & Transmission Line & 0.3399 & 0.4533 & 0 \\
\hline 8 & 28 & Transmission Line & 0.0636 & 0.2 & 0.0214 \\
\hline 6 & 28 & Transmission Line & 0.0169 & 0.0599 & 0.0065 \\
\hline
\end{tabular}


جايابى بهينه فيلتر يسيو در سيستم قدرت با استفاده از الكوريته كراف

مريم آقائى و على دستفان"

كروه قدرت، دانشكده مهيندسى برق، دانشكاه شاهرود، شاهرود، ايران.

ارسال r.

جكيده:

با توجه به افزايش ميزان بارهاى غيرخطى، سطوح هارمونيكى در سيستم قدرت افزايش بيدا كـردهاست.منابع اصلى توليـد هارمونيكـهـا شـامل ادوات

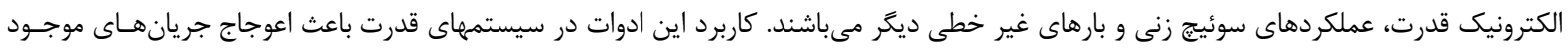

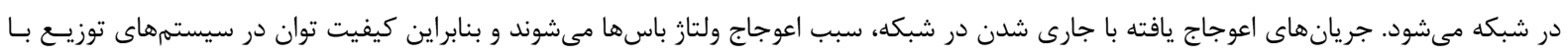

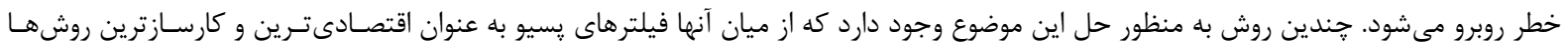

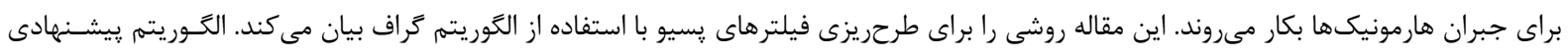

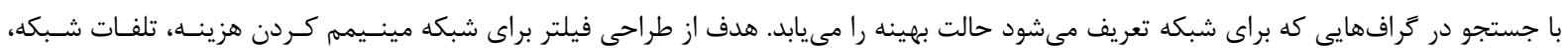

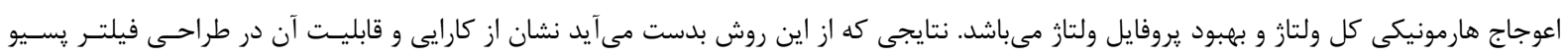
براى شبكه قدرت دارد. 